\title{
THE PREVALENCE OF MENTAL RETARDATION BY GENDER, AGE, AND AGE OF DIAGNOSIS AT NOBEL MEDICAL COLLEGE, BIRATNAGAR
}

\author{
Naba Raj Koirala, Ajay Kumar, Das and Santosh Kumar Bhagat
}

\begin{abstract}
:
Objectives: To evaluate the prevalence of mental retardation by gender and age of diagnosis at Nobel Medical College, Biratnagar.

Methods: The data of all mentally retarded children recorded within a period of one year from $01^{\text {st }}$ May 2011 to $30^{\text {th }}$ April 2012 is analyzed retrospectively. Age, gender, IQ scores, the age of diagnosis, and their living place were evaluated.

Results and conclusion: A total number 103 children attended the Psychiatric Out-patient Department of Nobel medical College and Teaching Hospital over the study period of one year. Out of all those 103 children, 67 children were with normal IQ scores, 7 with coexistence of epilepsy and other medical problems, and 3 children with incomplete case records, thus they were excluded from the study, and the subjects for further study was constituted by just 26 cases, who fulfilled the diagnostic criteria for Mental Retardation according to ICD-10.
\end{abstract}

The overall prevalence of mental retardation in our study was $25 \%$ and the distribution of mental retardation amongst all those 26 cases were as follows: 2 cases (8\%) were profound, 3 severe (12\%), 7 (27\%) were moderate and 9 (35\%) mild, and 5 (19\%) were borderline. Out of all those 26 mentally retarded children 11 were male (42\%) and $15(58 \%)$ were female, and of these cases, 07 were living in urban, and 19 in rural areas. Most of our cases were diagnosed between 6-10 years of age.

Key words: Mental Retardation, Nobel Medical College, IQ Score, Standford-Binet Intelligence scale.

\section{Introduction:}

Mental retardation (MR) is one of the most frequent disorders among children. The prevalence rate of $\mathrm{MR}$ varies across countries and regions, and this may be attributed to the variations in major classification systems, definitions, and methodologies. Due to these inconsistent criteria, there are considerable variations in the prevalence of MR from 2-85 per 1000.1,2 The diagnosis of MR mainly requires low general intellectual functions and age of onset before the age of $18^{1,2}$. In addition, deficits in adaptive behavior can also be added as a third component of the traditional definition of MR. The IQ score was the only tool to classify many children as mentally retarded ${ }^{2,3,4}$.

The etiologies of MR are multiple, and MR prevalence can also be influenced by social, economic, cultural, racial/ethnic, and other environmental factors including the demographics of age and gender ${ }^{5,6}$. However, epidemiological studies assessing 


\section{Original Article}

these relationships are scarce. An association between different forms of MR and social class was first proposed by Lewis ${ }^{6}$. There are many studies that have consistently found that the prevalence of MR was strongly associated with low socioeconomic status ${ }^{5,6}$. In developing countries, the effect of MR on individuals and society has been understudied and there are limited reports from these parts of world although it is likely to be more important. Due to inferior social conditions and limited occupational and educational opportunities, there are some differences in socioeconomic status between rural and urban areas.

The purpose of this study was to estimate the prevalence of MR amongst the children attending the Psychiatric Out-patient Department of Nobel Medical College, Biratnagar, and also to examine the age of diagnosis, gender, and location, of Mental retardation. The age, gender, IQ result, the age of diagnosis, and the location were evaluated in order to establish the differences that might affect the diagnosis and frequency of MR.

\section{Methodology:}

Nobel Medical College and teaching Hospital is a tertiary level hospital located in a major economic city in eastern part of Nepal. It provides both in-patient and out-patient services to a large number of patients residing in eastern part of Nepal and also nearby villages in India. All the necessary data for the study was obtained from the Psychiatric OPD of the Nobel Medical College and Teaching Hospital and was analyzed retrospectively. All care takers were informed about the possibility of use of these data in scientific studies and a verbal consent was obtained from them. An Approval was also obtained from the Ethics Committee of the Hospital. There were 103 children attended the psychiatric OPD of Nobel Medical college and Teaching Hospital over a period of one year, $01^{\text {st }}$ May 2011 to $30^{\text {th }}$ April 2012. Out of all those 103 children 67 children were with normal IQ scores, 7 with coexistence of epilepsy and other medical problems, and 3 children with case records that lacked gender, age, age at diagnosis, IQ scores, and/or living areas thus they were excluded from the study living only 15 cases for further analysis. The IQ scores of all those 15 cases were obtained to record the severity of mental retardation according to Stanford-Binet Intelligence Scales, 5th edition (Becker, 2003) ${ }^{4}$ as follows: 90-109: Average or Normal; 80-89: Borderline intelligence; 70-79: Mild MR; 50-69: Moderate MR; 20-49: Severe MR; and Below 20: profound. All available data were evaluated by using appropriate descriptive statistical tools.

\section{Results:}

In this study, 105 children attended the psychiatric out-patient department of Nobel Medical College and Teaching Hospital over a study period of one year $\left(01^{\text {st }}\right.$ May 2011 to $30^{\text {th }}$ April 2012). Out of all those 103 cases 77 cases were excluded from the study, hence the sample size for the study was comprised by 26 cases, whose intelligence scores on Standford-Binet intelligence scale were below than average, and also fulfilled the diagnostic criteria for mental retardation according to ICD-10. 
Table-1; Distribution of Cases according to Gender, Age at first diagnosis, area of living and Scores on Stanford-Binet intelligence Scores $(\mathbf{N}=\mathbf{2 6})$

\begin{tabular}{|c|c|}
\hline Gender & $\begin{array}{l}\text { Male }=11(42 \%) \\
\text { Female }=15(58 \%)\end{array}$ \\
\hline $\begin{array}{l}\text { Age at the } \\
\text { time of } \\
\text { diagnosis }\end{array}$ & $\begin{array}{l}\text { Below } 5 \text { years of age } \\
=2(7.69 \%) \\
6-10 \text { Years of age } \\
=13(50 \%) \\
10-15 \text { Years of age } \\
=7(26.92 \%) \\
\text { Age above } 16 \text { years } \\
=4(15.38)\end{array}$ \\
\hline $\begin{array}{l}\text { Area of } \\
\text { Living }\end{array}$ & $\begin{array}{l}\text { Urban }=07(26.92 \%) \\
\text { Rural=19 }(73.07 \%)\end{array}$ \\
\hline $\begin{array}{l}\text { Scores on } \\
\text { Stanford- } \\
\text { Binet } \\
\text { Intelligence } \\
\text { Scales }\end{array}$ & $\begin{array}{l}\text { Profound }=2(7.69 \%) \\
(\text { male }=0 ; \text { female }=2) \\
\text { Severe }=3(11.53 \%) \\
(\text { male }=1 ; \text { female }=2) \\
\text { Moderate }=7 \\
(26.92 \%)(\text { Male }=3 ; \\
\text { female }=4) \\
\text { Mild }=9(34.61 \%) \\
(\text { Male }=4 ; \text { Female }=5) \\
\text { Borderline }=5 \\
(19.23 \%)(\text { Male }=3 ; \\
\text { Female }=2)\end{array}$ \\
\hline
\end{tabular}

In our study Table 1 shows female preponderances over male (15 Vs. 11). Similarly majority of subjects who were diagnosed as cases of mental retardation were living in rural area compared to urban (19 Vs. 07, 73.07\% Vs. 26.92\%). The age group 6-10 years heavily predominated all other age group in regards to their age when they received the diagnosis of mental retardation first time in their life. Majority of cases according to scores on Stanford-Binet Intelligence scales were found to be suffering from mild ( $\mathrm{N}=9,34.62 \%$ ), and that was followed by Moderate level of mental retardation $(\mathrm{N}=7,26.92 \%)$. The overall prevalence rate of mental retardation in this study was equal to $25 \%$.

\section{Discussion:}

Mental retardation (MR) is defined as sub-average general intellectual functioning, which originated during developmental period and is associated with impairment in adaptive behavior. Mental handicap is the present term used for mental retardation. It is a condition of sub-average intellectual function combined with deficits in adaptive behavior. Mentally retarded children are one of the most frequently encountered, and most distressing, disabilities among children in most industrialized and developing countries world-wide ${ }^{6 .}$. Its prevalence rate varies considerably because of the varying criteria and methods used in the surveys, as well as differences in the age range of the samples, but its overall prevalence is equal to $1-3 \%$ among children all over the world ${ }^{1,2,8}$. It is more common in developing countries because of the higher incidence of injuries and anoxia around birth, and early childhood brain infections?. Although common amongst children, mental retardation is the most difficult categories of childhood disability to document epidemiologically, in part because its causes are multi-factorial. In less developed countries, like Nepal, the difficulties of documenting the causes of MR are compounded by lack of diagnostic 


\section{Original Article}

Mental Retardation: gender, age and age of diagnosis

services and routinely collected health data. Similarly many cases of mild retardation look like normal children and are diagnosed only after scholastic backwardness or failure. The effect of MR on individuals and societies has been underestimated in developing countries, and there are limited reports from this part of world although it is likely to be more important.

Previous studies have consistently shown that individuals from low socioeconomic status and rural areas are over represented among those with mild $\mathrm{MR}^{2,3,5,7,8}$. Some investigators have even suggested that mild MR rarely occurs among individuals from the upper socioeconomic groups unless other underlying neurological conditions are present $^{8}$. Unfortunately, comprehensive data on socioeconomic status of individuals in our study does not exist in database. Thus, the status of the patients has been roughly pointed out according to their living area.

It is generally an accepted notion that the annual income of individuals living in the urban area of eastern part of Nepal is higher than the rural area. Data on migration of individuals are also an important issue. However, our record does not include any information on these topics too. However we can extrapolate that the Nobel Medical College and Teaching Hospital is located in Biratnagar, the major economic zone of the country, and the available heath service is largely accessible to those who are living in an urban area, thus preventing many of earlier possible causes of mental retardation in later age. In our study mild MR was established more in the rural population, and this in accordance with previous studies ${ }^{2,3,5}$, $7,9,10,11,12$. In addition, the low percentage of borderline cases in our study may also likely to be explained on the ground of cultural variation prevalent in our society, where most of the children mainly male works in laboring jobs or in agriculture and constitutes as a major work force and may easily be ignored ${ }^{11,12,13}$. This may explain why the borderline MR was lower in our study. The female preponderances over male in our study may also be explained with support of the prevalent culture in the society, where female children are mostly engaged in the domestic works in their earlier age as compared to male and their incapacity at domestic works and later marital life is easily identifiable by the caretakers. In our study, the prevalence rate of mental retardation was 25 percent, and it likely to be matched with other studies reported in the country ${ }^{2,3,11,14,15,16}$.

\section{References:}

1.Accordo PJ, Capute AJ. Mental Retardations. Ment Retard Dev $\quad$ Disabil Res Rev 1998; 4: 2-5.

2.Roeleveld N, Zielhuis GA, Gabreels F.The prevalence of mental retardation: a critical review of recent literature. Dev Med Child Neurol 1997; 39: $125-132$.

3.Kiely M. The prevalence of mental retardation. Epidemiol Rev 1987; 9: 194-218.

4. Becker, K. A. Stanford-Binet Intelligence Scales, Fifth Edition. Itasca, IL: Riverside Publishing, 2003.

5.Croen LA, Grether JK, Selvin S. The epidemiology of mental retardation of unknown cause. Pediatrics 2001; 107: E86.

6.Drews CD, Yeargin-Allsopp $M$, Decoufle $P$, Murphy CC. Variation in the influence of selected sociodemographic risk factors for mental retardation. Am J Public Health $\quad$ 1995; 85: 329-334.

7.Leonard H, Petterson B, De Klerk N, Zubrick SR, Glasson E, Sanders R, et al. Association of sociodemographic characteristics of children with intellectual disability in Western Australia. Soc Sci Med 2005; 60: 1499-1513.

8.Stromme P, Magnus P. Correlations between socioeconomic status, IQ and aetiology in mental retardation: a population based study of Norwegian children. Soc Psychiatry Psychiatr Epidemiol 2000; 35: $12-18$.

9.Islam S, Durkin MS, Zaman SS. Socioeconomic status and the prevalence of mental retardation in 


\section{Original Article}

Bangladesh. Ment Retard 1993; 31: 412-417.

10.Fernell E. Mild mental retardation in schoolchildren in a Swedish suburban

municipality: prevalence and diagnostic aspects. Acta Paediatr 1996; 85: 584-588.

11.Anupam Pokharel, Saroj P. Ojha, Naba Raj Koirala, et al. A profile of the children and adolescence referred by paediatricians to the child guidance clinic of Tribhuvan University Teaching Hosiptial. Nepalese Journal of Psychiatry (2001), Vol. 2, No. 4

12.Nepal, M.K., Sharma, P. \& Gurung, C. K. The first child psychiatric clinic: an initial appraisal. NEPAS, 7 (1), 71-75, 1988.

13.Ojha, S. P. Emotional and Behavioral Problems in physically Disabled Children and Adolescents. MD
Mental Retardation: gender, age and age of diagnosis

Thesis, Institute of Medicine, Maharajgung, Kathmandu, 1999.

14.Regmi, S.K., Khalid, A., Nepal, M.K. \& Pokharel, A. A study of sociodemographic characteristics and diagnostic profile in psychiatric outpatients. Nepalese Journal of Psychiatry,1999; 1(1), 26-33.

15.Regmi, S.K., Nepal, M.K. Khalid, A., Sinha, U.K., Kiljunen, R., Pokharel, A. \& Sharma, S.C. A study of Children and Adolescents attending the Child Guidance Clinic of a General hospital. Nepalese Journal of Psychiatry, 2000; 1(2), 90-97.

16.Shrestha, D.M. Neuropsychiatric problems in children attending a general psychiatric clinic in Nepal. Nepal Paediatric Society Journal, 1986; (1), 97-101.

Correspondence Address: Naba Raj Koirala, Head, Deparment of Psychiatry and Mental Health, Nobel Medical College and Teaching Hospital, kanchanbari-5, Biratnagar, Nepal. 